\title{
Measuring Hearing Aid Benefit in Nicaragua using Cultural Considerations
}

\author{
Letitia White, Paige Dietz, Beth Mincey, Lisa Proctor, Abdullah Jamos, Edith Bobbitt-Boyce, Sarah Barber \\ Communication Sciences and Disorders Department, Missouri State University, MO, United States
}

\begin{abstract}
Purpose: Hearing aid outcome measures often do not account for cultural differences among patients. The purpose of the current study was two fold. First, outcomes on the International Outcome Inventory for Hearing Aids (IOI-HA) for individuals in rural Nicaragua were compared to reported results from other countries. Second, interviews were used to develop a culturally relevant tool that could be appended to the IOI-HA to assess hearing aid benefit for patients fitted with amplification in rural Nicaragua.
\end{abstract}

Methods: The IOI-HA was administered and qualitative interviews were conducted. Interview respondents were asked about sounds that are part of their everyday lives. Using the data from the interviews, areas were identified in which success with hearing aids should be assessed.

Results: Responses on the IOI-HA for adults in the current study were comparable to reported results from other countries. Interview responses from over half of participants fell into four broad areas: speech (in quiet and noise), traffic sounds, listening to music, and birds.

Conclusions: Nicaraguan responses on the IOI-HA were similar to previous reports from other countries. However, it was difficult for patients to complete the questionnaire independently, supporting the need for a culturally relevant assessment tool. Based on the literature review and the responses of participants, a hearing aid benefit tool was constructed for use with amplification recipients in Nicaragua.

Keywords: Hearing aid benefit, Outcome measures, IOI-HA, Graphic Assessment of Benefit

\section{INTRODUCTION}

Since 2012, Missouri State University's Department of Communication Sciences and Disorders has hosted an annual short-term Study Away Program to Nicaragua. The goals of the program are to increase the cultural awareness of students, to provide opportunities for community engagement, and to provide speech and hearing related services to Nicaraguans. As part of the program, several patients were fitted with hearing aids. To measure the amount of benefit obtained by those patients, it was important to consider the culture of Nicaragua and how it influences service provision. According to the United Nations Universal Declaration on Cultural Diversity, culture is defined as "the set of distinctive spiritual, material, intellectual and emotional features of society or a social group, and that it encompasses, in addition to art and literature, lifestyles, ways of living together, value systems, traditions and beliefs" [1]. Cultural competence is as important in maximizing outcomes in service delivery as clinical competence [2].

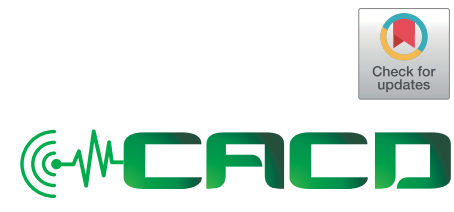

Received: June 30, 2017

Revision: November 1, 2017

Accepted: December 20, 2017

\section{Correspondence:}

Letitia White

Communication Sciences and Disorders Department, Missouri State University, 901 South National, Springfield, MO 65897, United States

Tel: 417 836-4710

Fax: 417 836-4242

E-mail: LetitiaWhite@missouristat.edu

The authors would like to acknowledge Todd Daniel, Ph.D., Director of the RStats Institute at Missouri State University, for his contributions to the statistical analysis of this research. The authors would also like to express gratitude to those in Nicaragua that assisted and participated: to Barry and Christine Lydon for their support and assistance; to the interpreters, without whom, this work would not be possible; to the teachers, families and patients that we serve.

This research was presented at the American Academy of Audiology's Annual Convention, Phoenix Arizona, in May 2016.

(C) 2017 The Korean Association of SpeechLanguage Pathologists

This is an Open Access article distributed under the terms of the Creative Commons Attribution Non-Commercial License (http:// creativecommons.org/licenses/by-nc/4.0/) which permits unrestricted non-commercial use, distribution, and reproduction in any medium, provided the original work is properly cited. 
With this in mind, the goal of the present study was to develop a means to evaluate hearing aid outcomes in a culturally competent manner.

The World Health Organization's International Classification of Impairments, Activities, and Participation has a specified framework for outcome measurements. Within this framework, a hearing loss is an impairment that leads to activity and participation limitations. In many instances, hearing loss is treated with amplification. Quantification of the amount of hearing aid benefit received by a recipient of amplification and the associated reduction of impairment related to a hearing loss is achieved through objective (i.e., real ear measures, speech mapping) and/or subjective tools (benefit questionnaires). While objective measures assess the reduction in impairment that occurs when amplification is in place, subjective measures evaluate the reduction in disability and handicap resulting from amplification [3]. Subjective measures take into account personal factors that may influence hearing aid success or failure, attempting to provide a measure that reflects the benefit provided by hearing aids in everyday life. Questionnaires filled out by the patient are a common way to subjectively measure perceived benefit.

Two of the original questionnaires developed to evaluate hearing aid performance are the Hearing Aid Performance Inventory (HAPI) and the Profile of Hearing Aid Performance (PHAP). The HAPI, developed in 1984, focused on four main scenarios that affect hearing aid benefit: speech in quiet, speech in noise, speech with little information in the signal, and non-speech or non-live speech [4]. The PHAP, developed in 1990, measured two areas of hearing aid performance: speech communication in everyday settings and reactions to environmental sounds [5]. The PHAP was different from the HAPI in that it evaluated the detrimental effects of environmental sounds after amplification. Slight modifications to the PHAP allow hearing aid benefit to be derived [5]. Subsequent versions of the PHAP include the Profile of Hearing Aid Benefit (PHAB), developed in 1990 [5] and the Abbreviated Profile of Hearing Aid Benefit (APHAB), developed in 1999 [6]. The aforementioned questionnaires and many of the others available today do not account for cultural differences among patients. For example, the PHAP includes questions such as "I have trouble understanding the dialogue in a movie or at the theater" [5]. Patients in developing countries may not have access to theaters. Other items on the PHAP that are not relevant to all people include questions related to air conditioners, smoke detectors, and doctor's offices.
To address the need for a tool that could be administered in developing countries, the International Outcome Inventory for Hearing Aids (IOI-HA) was created [7]. It is available in 21 languages and was developed at an international workshop on Self-Report Outcome Measures in Audiological Rehabilitation [6]. The IOI-HA was devised for administration as part of a research protocol to allow researchers to make comparisons across studies that otherwise might not be comparable. It is brief, consisting of 7 questions on a 5 point Likert scale that are filled out by the patient. It was designed at a reading level that would be accessible to most. The questions are general enough to allow use across different studies. Many clinicians have found it to be acceptable as a tool to assess hearing aid effectiveness [6]. It was written to avoid cultural bias and negative connotations. The general nature of the questions are such that they do not relate to specific lifestyles or traditions. For example, the IOI-HA asks patients to consider a situation where they wish to hear better. It then asks how much difficulty they still have in that situation. Clearly, this eliminates bias because the question can be applied to situations across cultures. The questions on the IOI-HA address self-report outcome measures that are relevant in a hearing aid fitting: hearing aid usage, benefit, residual activity limitations, satisfaction, residual participation restrictions, impact on others, and quality of life [8]. Cox and Alexander [6] reported that the most straightforward way to interpret results from the IOI-HA is the distribution of the total score for each patient. Because the amount of specific information the IOI-HA supplies about hearing aid effectiveness in varied listening environments is limited [8], an alternate questionnaire is required to obtain situation-specific outcome information. As mentioned earlier, many currently available questionnaires focus on reactions to environmental sounds (i.e., movie theater, air condition, smoke detector), some of which were not commonly encountered by the patients seen by the authors.

In addition to lifestyle and environmental differences across cultures, other differences observed related to the use of language could theoretically skew results of published questionnaires. For example, Nicaraguan's are known to answer questions affirmatively, avoiding negative connotations and the perception of rudeness [12]. This cultural aspect may make it challenging for some individuals to provide feedback about the amount of benefit being received from hearing aids when only questionnaires with closed-ended questions are used. Further, a questionnaire that evaluates hearing aid effectiveness with consideration to the sounds that are common in de- 
veloping countries is currently not available. While the IOIHA is available to provide some information, it was designed for administration as part of a research protocol or test battery. A questionnaire that is able to assess subjective benefit in a culturally sensitive manner would significantly improve the accuracy of assessment. Therefore, the purpose of the present study is to develop a culturally sensitive tool to evaluate hearing aid benefit in rural Nicaragua. Rural Nicaragua was chosen as the focus of this study because the authors have fit many patients with hearing aids there as part of a Study Away Program at Missouri State University that has been ongoing since 2012. The IOI-HA was administered to facilitate future comparisons to other studies.

In order to develop a culturally sensitive tool, it was first necessary to understand the culture of Nicaragua. Many factors influence the culture, including the environment, the educational system, the health/medical system, religion, and values. Approximately 6 million people live in Nicaragua, with $30 \%$ of the total population comprised of individuals under the age of 14 years [9]. Spanish is the official language, spoken by over 70 percent of the population [10]. The economy of $\mathrm{Ni}$ caragua is based on agriculture [11]. There is plentiful wildlife, including a variety of birds often seen in settled parts of the country [12].

Nicaragua has a formal education structure that is free and compulsory, from ages 5 to 11 [9]. The literacy rate among adults between the ages of $15-24$ is $92 \%$, much better than that of adults over age 65 (56\%). For adults over age 15, the literacy rate is $82 \%$ [9]. The average reading level in Nicaragua is 5.6 years, but only 3.6 years in rural areas [13].

Although officially Nicaragua is a secular state, most Nicaraguans are Roman Catholic or belong to Protestant denominations [10]. Due to the predominantly devout Catholic population, Christian religious holidays are celebrated by Nicaraguans [12]. In addition, annual celebrations are held for each patron saint [14]. Codified in the Nicaraguan constitution, religious freedom and tolerance is promoted by the government. Religion influences Nicaraguans heavily and is often heard in their speech with the use of the word "God".

Although there are obviously individual and group difference amongst Nicaraguans, the literature does report some generalities related to Nicaraguan culture. For example, like other Central American countries, the people of Nicaragua place high importance on family and the protection of personal dignity [10]. The idea of personal dignity forms an overall feeling of national pride among Nicaraguans [12]. Traditional family roles remain the standard, with the men working in fields or factories, women working domestically, and children helping with chores such as farming, small business, etc. [14]. Nicaraguans hold family relationships with high esteem and include relatives beyond the nuclear family unit [12]. From a very early age, children learn to respect their elders [12].

Nicaraguans usually spend their leisure time in groups, enjoying music and food [14]. Since music is an important pastime for Nicaraguans, local musicians are frequently heard around towns and cities infusing a mixture of Spanish and traditional native Indian styles [14]. The national instrument of Nicaragua is the marimba [12].

In has been reported that the people of Nicaragua are very polite, often providing responses reflecting what they feel "you want to hear" in order to avoid the perception of rudeness or negativity [12]. In the experience of the authors, many Nicaraguans are hesitant to provide negative responses regarding the performance or fit of their hearing aids, so it can be difficult to make fitting adjustments. Gratitude is an important cultural attitude and charity is highly valued [14]. Reflecting the strong belief in mutual respect, relationships (personal or professional) are built on attention to individual feelings and care of personal circumstances.

Given that the IOI-HA is best utilized when combined with another subjective measurement tool, and there are no culturally sensitive tools available to append to the IOI-HA, the purpose of this study was to (i) administer the IOI-HA in Nicaragua for comparison to data obtained in other countries and (ii) interview Nicaraguans in an effort to gain an understanding of their everyday lives and the sounds that are common (and important) to them. Interview questions were broad and open ended. The information obtained, when combined with the review of the culture, was used to guide the development of a culturally sensitive measure of hearing aid benefit.

\section{METHODS}

\section{Participants}

Thirteen children with hearing impairment (ages 5-17) and thirteen adults with hearing impairment (over age 18) living in rural Nicaragua completed the IOI-HA questionnaire. Participants completing the interview consisted of eleven hearing aid users (seven children - ages 5-17; four adults - over age 18), four community members, five parents of hearing-impaired children, and five teachers. Many of the participants with hearing impairment received services as part of the Mis- 
souri State University's Department of Communication Sciences and Disorders mission to provide speech, language, and hearing related services to hearing impaired people in rural Nicaragua. All participants or participants' guardians signed a consent form that was approved by the Missouri State University Institutional Review Board.

\section{Materials}

The Spanish version of the IOI-HA was utilized. It was obtained from the International Collegium of Rehabilitative $\mathrm{Au}-$ diology self-report repository at http://icra-audiology.org/Repository/self-report-repository/Survey. In addition, interview questions were developed. The interview questions were intended to be broad and open ended, to allow participants to describe their daily life, as well as sounds that are common in their daily life. Participants answered the following questions: "What situations are important to you in terms of hearing ability?"

"What environmental sounds do you hear on a daily basis?"

"If you lost your hearing, what sounds and situations would you miss the most?"

"If you had a child with hearing loss, what sounds and situations do you think they would miss the most?"

\section{Procedures}

\section{IOI-HA Questionnaire}

The IOI-HA was administered to 26 hearing aid users. Communication between the researcher and participant was possible through an interpreter. All interpreters had worked previously with MSU teams and were familiar with terminology related to audiology as well as the purpose of the questionnaire. Participants completed all seven questions on the Spanish version of the IOI-HA using paper and an ink pen.
Eleven out of thirteen adults were able to complete the IOIHA with minimal assistance. Two adults were unable to read and required oral administration of the questions by an interpreter. The children had the questionnaire read to them by an interpreter and provided verbal responses.

\section{Interviews}

Twenty-five participants were interviewed about everyday life in Nicaragua. Eleven were hearing aid users who also completed the IOI-HA. The remainder consisted of community members, parents and teachers. The interview was conversational in nature. Answers given were recorded using pen and paper.

\section{RESULTS}

\section{IOI-HA Questionnaire}

The average response on the IOI-HA was 3.97 from the adult population and 4.23 from the pediatric population. This gives an overall average response for all participants of 4.10. Results of the IOI-HA are depicted in Figure 1. There were two missing data points because two participants each left one question unanswered. To replace the missing data, the mean of the other six questions was calculated for each participant.

A single sample t-test was conducted to determine if a statistically significant difference existed between the IOI-HA values obtained in Nicaraguan adults compared to studies of adults in other countries. Table 1 lists the countries and the mean scores on the IOI-HA for each country $[5,6,13-17)$. Nicaraguan adult participant responses $(\mathrm{M}=3.97 ; \mathrm{SD}=.72)$ were not found to be statistically different when compared to other reported data. $\mathrm{T}$ and $P$ values for each comparison are presented in Table 1.

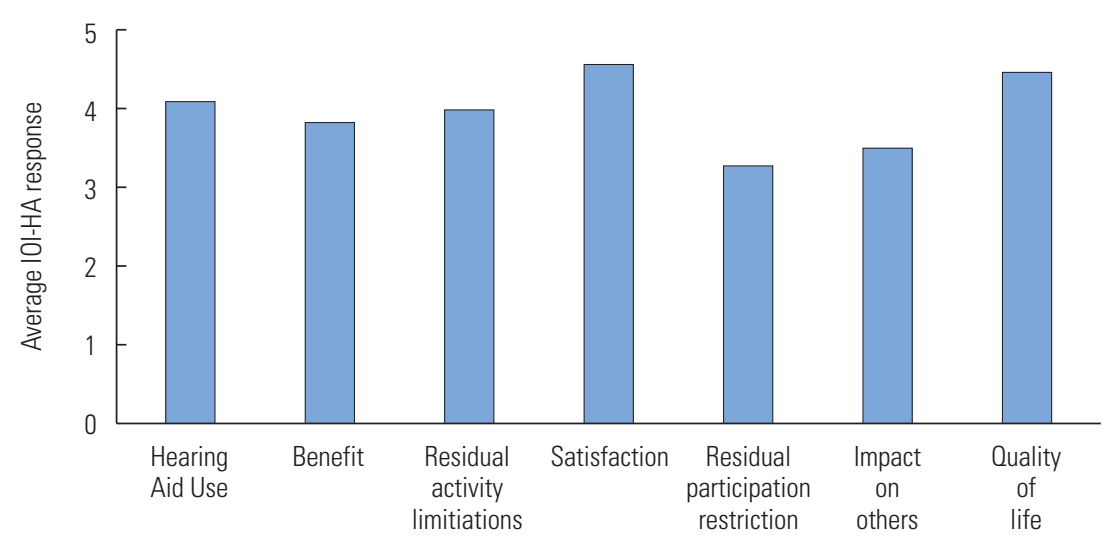

Figure 1. Overall average response for each question of the IOI-HA. 
Table 1. The mean score of the seven questions on the IOI-HA in the literature, as compared to adult participants in the current study

\begin{tabular}{lccc}
\hline Country (Language) & Mean score & T-Value & P-Value \\
\hline Germany (German) & 3.98 & 0.01797 & 0.98596 \\
Australia (English) & 3.91 & 0.07902 & 0.93832 \\
United States of America (English) & 3.80 & 0.23143 & 0.82088 \\
China (Chinese) & 3.76 & 0.28685 & 0.77912 \\
The Netherlands (Dutch) & 3.64 & 0.45311 & 0.65856 \\
Nigeria (English) & 3.63 & 0.46696 & 0.64889 \\
Egypt (Arabic) & 2.26 & 2.08801 & 0.05878 \\
\hline
\end{tabular}

Table 2. Description of categories from responses of interviews

\begin{tabular}{|c|c|c|}
\hline Category & & Description \\
\hline \multirow[t]{2}{*}{ Speech } & Quiet & $\begin{array}{l}\text { One-on-one conversations with friends, family, } \\
\text { co-workers, students, etc. }\end{array}$ \\
\hline & Noise & $\begin{array}{l}\text { Conversations in groups with friends, family, } \\
\text { co-workers, students, etc. }\end{array}$ \\
\hline \multirow[t]{5}{*}{ Environmental } & Traffic & $\begin{array}{l}\text { Vehicle engines, motorcycles, sirens, car horns, } \\
\text { etc. }\end{array}$ \\
\hline & Wind & Wind blowing through trees, etc. \\
\hline & Animals & $\begin{array}{l}\text { Animal sounds (other than birds and dogs) } \\
\text { including cats, frogs, horses, cows, etc. }\end{array}$ \\
\hline & Dogs & Dogs barking. \\
\hline & Birds & Birds chirping. \\
\hline \multirow[t]{3}{*}{ Activities } & Church & Religious leader in larger room. \\
\hline & Television & Television shows. \\
\hline & Music & $\begin{array}{l}\text { Live music (inside and outside), recorded } \\
\text { music, etc. }\end{array}$ \\
\hline \multirow[t]{3}{*}{ Other } & Children & Talking, laughing, playing, crying, etc. \\
\hline & Fireworks & $\begin{array}{l}\text { Fireworks during community celebrations, } \\
\text { holidays, etc. }\end{array}$ \\
\hline & Telephone & Cell phone and landlines. \\
\hline
\end{tabular}

\section{Interviews}

Interview participants were asked to describe sounds heard in their daily lives. The responses given fell into several categories. As can be seen from Table 2, the categories relate to speech (in quiet and noise), environmental sounds (animals, traffic noise, wind), activities (listening to music, attending church, hearing the television), children, fireworks and the telephone. The frequency of responses for each category is shown in Figure 2. More than half of respondents listed speech in quiet and noise, traffic sounds, music and birds as sounds that are part of their everyday lives.

\section{DISCUSSION}

The results of the IOI-HA administered in rural Nicaragua in the current study were not statistically different from many previously reported results from other countries (see Table 1). Given the expectation of similar results across cultures, this would indicate that the IOI-HA is appropriate for use in Nicaragua. However, some observations were made while administering the IOI-HA questionnaire in Nicaragua. First, most children and several adults in the Nicaraguan study could not sufficiently complete the questionnaire independently. This is not surprising, as the average reading level in rural Nicaragua is lower than the reading level of the IOI-HA [13]. Using the Flesch Kincaid readability statistic, the overall reading level of the IOI-HA (English version) is 7.6 (seventh grade, 6 months). However, multiple individual questions are at, and over, the tenth grade reading level. Since all translated versions of the IOI-HA were written to be as similar to the English version as possible, one can assume the Spanish version has a comparable reading level. The average education level in Nicaragua is 5.6 years but only 3.6 years in rural areas similar to where the

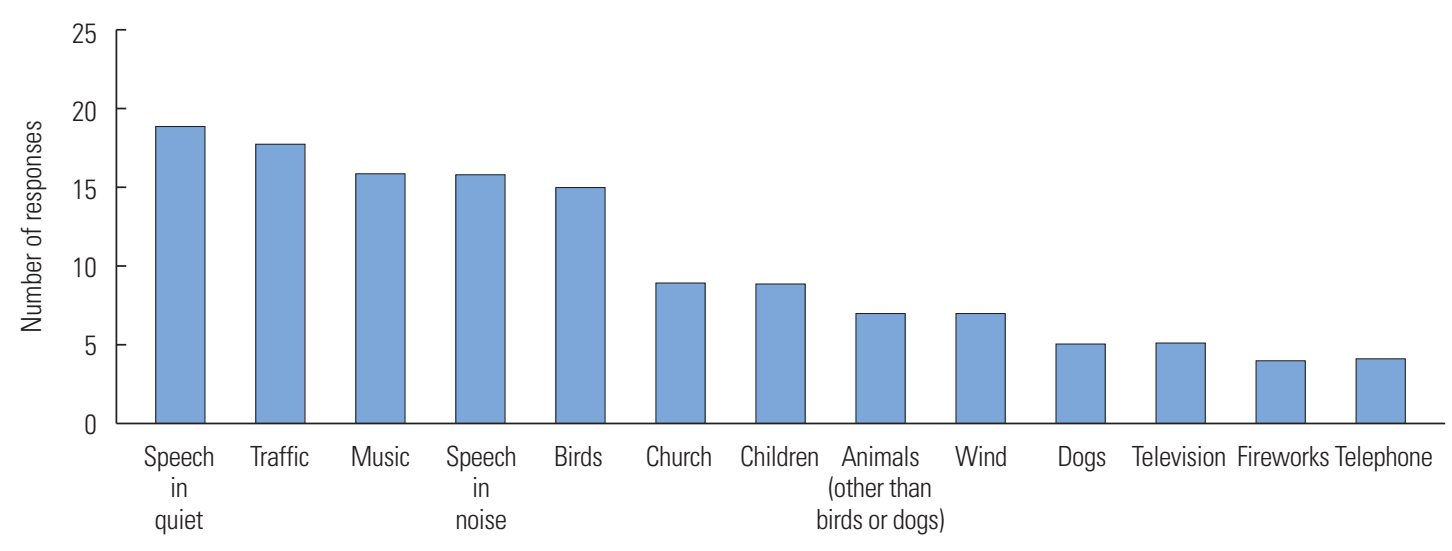

Figure 2. Summary of the frequency of responses by participants to interview questions regarding sounds heard in everyday life. 
current study took place [13]. This suggests that many people in Nicaragua, particularly the elderly and those from rural areas, may have difficulty comprehending the IOI-HA. This highlights the importance of adaptions to administration based on literacy skills of participants.

An initial concern was that cultural differences could affect the participants' responses to the IOI-HA. Some questions employ negative wording such as 'troubled, 'bothered, and 'difficulty'. It has been reported that Nicaraguans may tend to provide responses that would avoid the perception of rudeness or negativity [12]. It was hypothesized that this may have caused some participants to feel they could not answer honestly to these negatively worded questions. However, the score of the Nicaraguan participants did not vary greatly from those of participants in other countries.

Results of the IOI-HA from Nigeria (mean scores $=3.63$ ) are of special interest in regards to the present study, as Nigeria is a developing country [18]. However, the participants who completed the IOI-HA in Nigeria were those of a well-established private pay hearing center. This suggests that these patients are of a higher socioeconomic class than other developing populations. Therefore, comparing results from Nigeria and other populations in developing counties should be done with caution, as participants in the current study, done in Central America, received free amplification. Research by Kim and Koo [20] indicated that offering a product as a free gift will influence the consumer's value of that gift. It is possible that the free amplification given to the patients in the current study may have caused them to report greater satisfaction.

In summary, the Nicaragua participants did not provide more favorable ratings regarding hearing aid satisfaction when compared to other countries, as measured by the IOIHA. However, given the reports of the tendencies of Nicaraguans to provide affirmative answers and appear polite [12. as well as the authors' personal experiences in this regard, additional research is needed in order to confirm that satisfaction ratings are accurate.

Responses from the interviews conducted were reviewed and independently categorized by two judges (both authors). Using these categories and knowledge obtained from the research of Nicaraguan culture, a tool was created to subjectively assess hearing aid benefit. Questions were developed for both adult and pediatric populations. Because of the variability of the literacy rates, and the difficulty many patients in the current study exhibited in completing the IOI-HA independently, the tool developed herein was designed to be highly visual. The newly developed tool is titled Graphic Assessment of Amplification Benefit (GAAB) and is available in an adult version (GAAB-A) and a pediatric version (GAAB-P). Samples are shown in Appendix I. Utilizing an interpreter, questions were translated to Spanish by an individual fluent in the language and familiar with the culture. Graphic design services were solicited in order to develop the tool and incorporate graphics for each question. Four versions of the tool are available: GAAB-A English, GAAB-A Spanish, GAAB-P English, and GAAB-P Spanish. Rating scales were developed for the pediatric and adult versions.

\section{CONCLUSION}

Outcomes for the IOI-HA were similar for Nicaraguans as compared to outcomes reported in other countries. However, the IOI-HA was designed to be used in conjunction with other validation measures. The interviews conducted in Nicaragua provided information that was used to develop a tool to measure hearing aid benefit (in the cultural context being studied). The goal of future studies will be to evaluate this tool in rural Nicaragua when administered in conjunction with the IOI-HA. This research will assess the reliability and validity of both the pediatric and adult versions of the GAAB. Given the relatively small sample sizes in the current study, it is important to interpret the findings with caution, and that future research validates the tools developed. Additionally, it is important to consider the construct of essentialism. Essentialism defines groups as being "essentially" different. In defining group characteristics, care providers must be cautious not to stereotype their patients. In summary, the authors believe that developing culturally sensitive measurement tools will increase the likelihood of positive outcomes for hearing aid recipients in developing countries. However, this proposition will need to be rigorously tested by future studies.

\section{REFERENCES}

1. UNESCO. Universal Declaration on Cultural Diversity. Paris: United Nations Educational, Scientific and Cultural Organization. 2001. Available from http://unesdoc.unesco.org/images/0012/001271/127162e. pdf.

2. Wolf, KE. Cultural competence in audiology. The ASHA Leader;9(7):7-8.

3. Johnson CE, Danhauer JL. Handbook of outcome measurement in audiology. Canada: Thomson Delmar Learning; 2002.

4. Walden BE, Demorest, ME, Hepler EL. Self-report approach to assessing benefit derived from amplification. JSHR. 1984;27:49-56. 
5. Cox R, Gilmore C. Development of the profile of hearing aid performance (PHAP). JSHR. 1990;33:343-357.

6. Cox R, Alexander G, Gray G. Personality and the subjective assessment of hearing aids. J of the Amer Acad of Audiol. 1999;10:1-13.

7. Cox R, Alexander G. The international outcome inventory for hearing aids (IOI-HA): psychometric properties of the English version. Int J of Audiol. 2002;41:30-35.

8. Hickson L, Clutterbuck S, Khan A. Factors associated with hearing aid fitting outcomes on the IOI-HA. Int J of Audiol. 2010;49:586595.

9. UNESCO Institute for Statistics. (n.d.). Nicaragua: Education and Literacy. Retrieved June 21, 2017 from http://uis.unesco.org/en/ country/NI.

10. Walker TW, Wade CJ. Nicaragua: Living in the Shadow of the Eagle. Boulder, CO: Westview Press; 2011.

11. Foroohar M. The Catholic Church and Social Change in Nicaragua. Albany, NY: State University of New York Press; 1989.

12. Rounsefell E. Adventure guide Nicaragua. Edison, NJ: Hunter Publishing; 2008.

13. UNIDOS Nicaragua [Internet]. (2015). Available from http://uni- dosnicaragua.org/our-work/life-in-nicaragua.

14. White SF, Calderon E. Religion and Religious Celebrations. In Culture and Customs of Nicaragua. Santa Barbara, CA: Greenwood; 2008.

15. Heuermann H, Kinkel M, Tchorz, J. Comparison of psychometric properties of the international outcome inventory of hearing aids (IOI-HA) in various studies. Int J of Audiol. 2005;44:102-109.

16. Liu H, Zhang H, Liu S, Chen X, Han D, Zhang L. International outcome inventory for hearing aids (IOI-HA): results from the Chinese version. Int J of Audiol. 2011;50:673-678.

17. Kramer S, Goverts S, Dreschler W, Boymans M, Festen J. International outcome inventory for hearing aids (IOI-HA): results from The Netherlands. Int J of Audiol. 2002;41:36-41.

18. Olusanya B. Self-reported outcomes of aural rehabilitation in a developing country. Int J of Audiol. 2004;43:563-571.

19. Mustafa M. Norms for the arabic international outcome inventory for hearing aids. Internet J of Otorhinol. 2004;4.

20. Kim H, Koo J. Stand-alone sale of a free gift: is it effective to accentuate promotion value? Social Behav \& Personality: an Int J. 2015; 43:15093-1606. 
Appendix I. Sample Slides from the Pediatric Version (English)

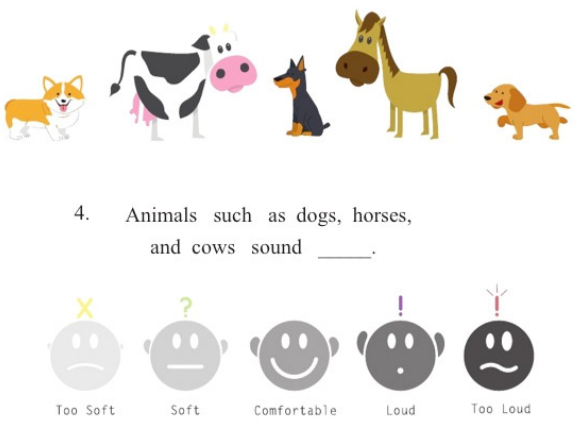

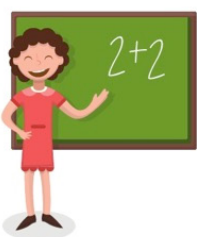

9. My teacher's voice sounds

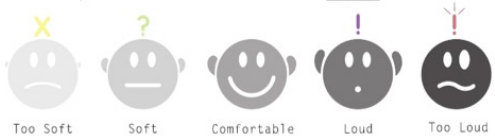

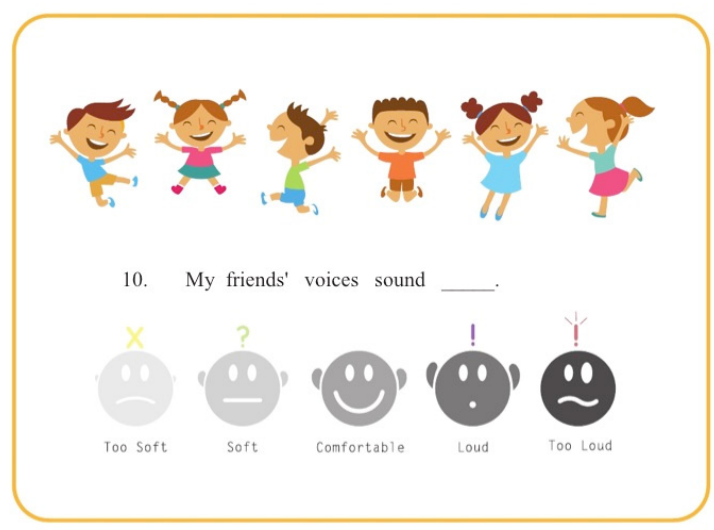


Appendix I. Sample Slides from the Adult Version (English)
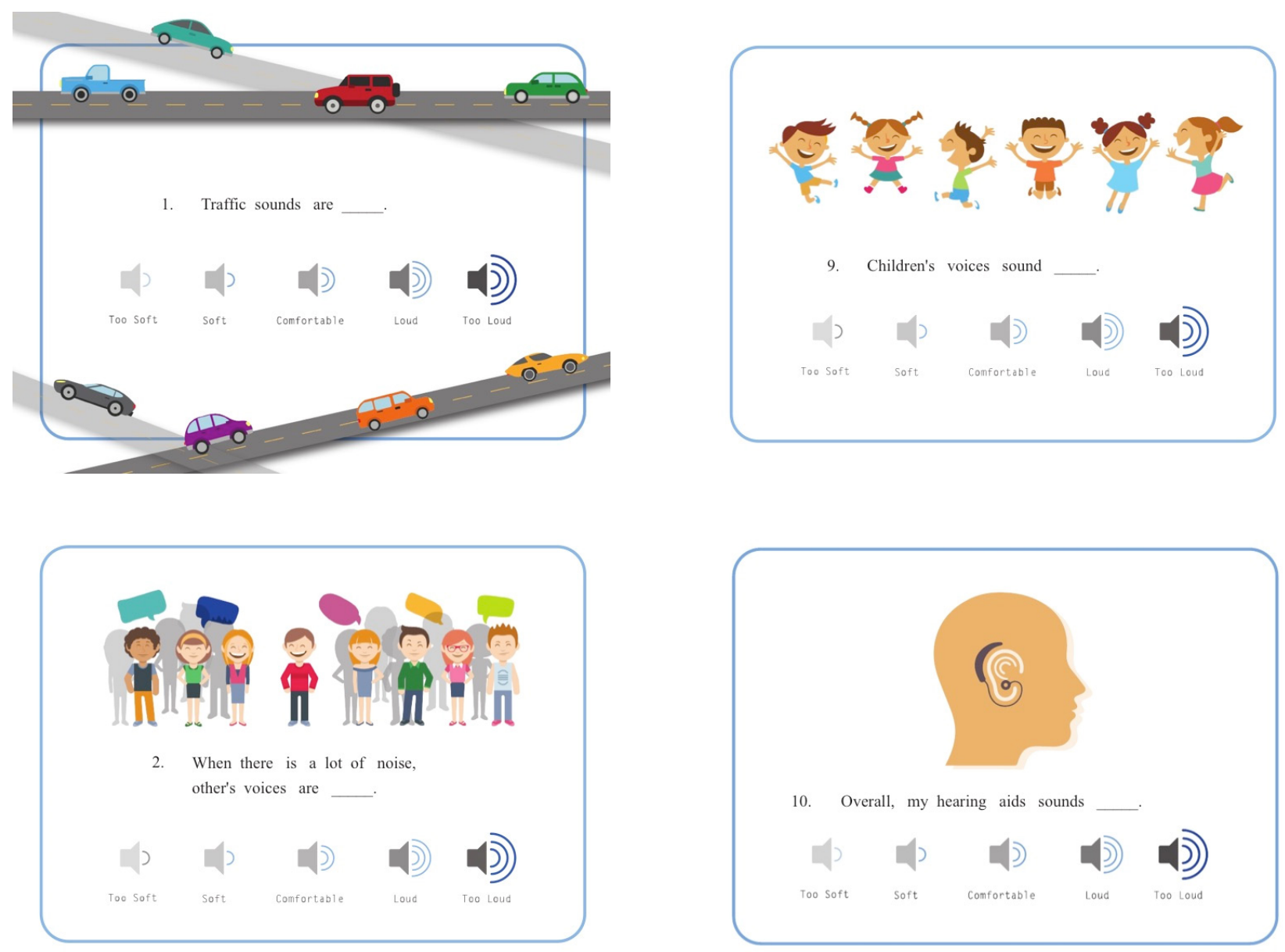